\title{
Erratum to: Load-dependent movement regulation of lateral stretch shortening cycle jumps
}

\author{
Jana Fleischmann • Dominic Gehring • \\ Guillaume Mornieux $\cdot$ Albert Gollhofer
}

Published online: 4 July 2010

(C) Springer-Verlag 2010

\section{Erratum to: Eur J Appl Physiol}

DOI 10.1007/s00421-010-1476-9

Unfortunately, the online publication of the original article contains errors in the graphics.

In Fig. 4b, the abbreviation 'VLVL' should actually be 'VL'.

In Fig. $4 \mathrm{~b}, \mathrm{c}$, the first abbreviation on the $x$-axis should be 'BF' instead of 'PL'.

In Fig. 5d, the abbreviation 'TIB' should be 'TA'.

The corrected version of the figures is presented for better understanding and readability.

The online version of the original article can be found under doi:10.1007/s00421-010-1476-9.

J. Fleischmann $(\bowtie) \cdot$ D. Gehring · G. Mornieux · A. Gollhofer Department of Sport Science, University of Freiburg,

Schwarzwaldstr. 175, 79117 Freiburg, Germany

e-mail: Jana.Fleischmann@sport.uni-freiburg.de
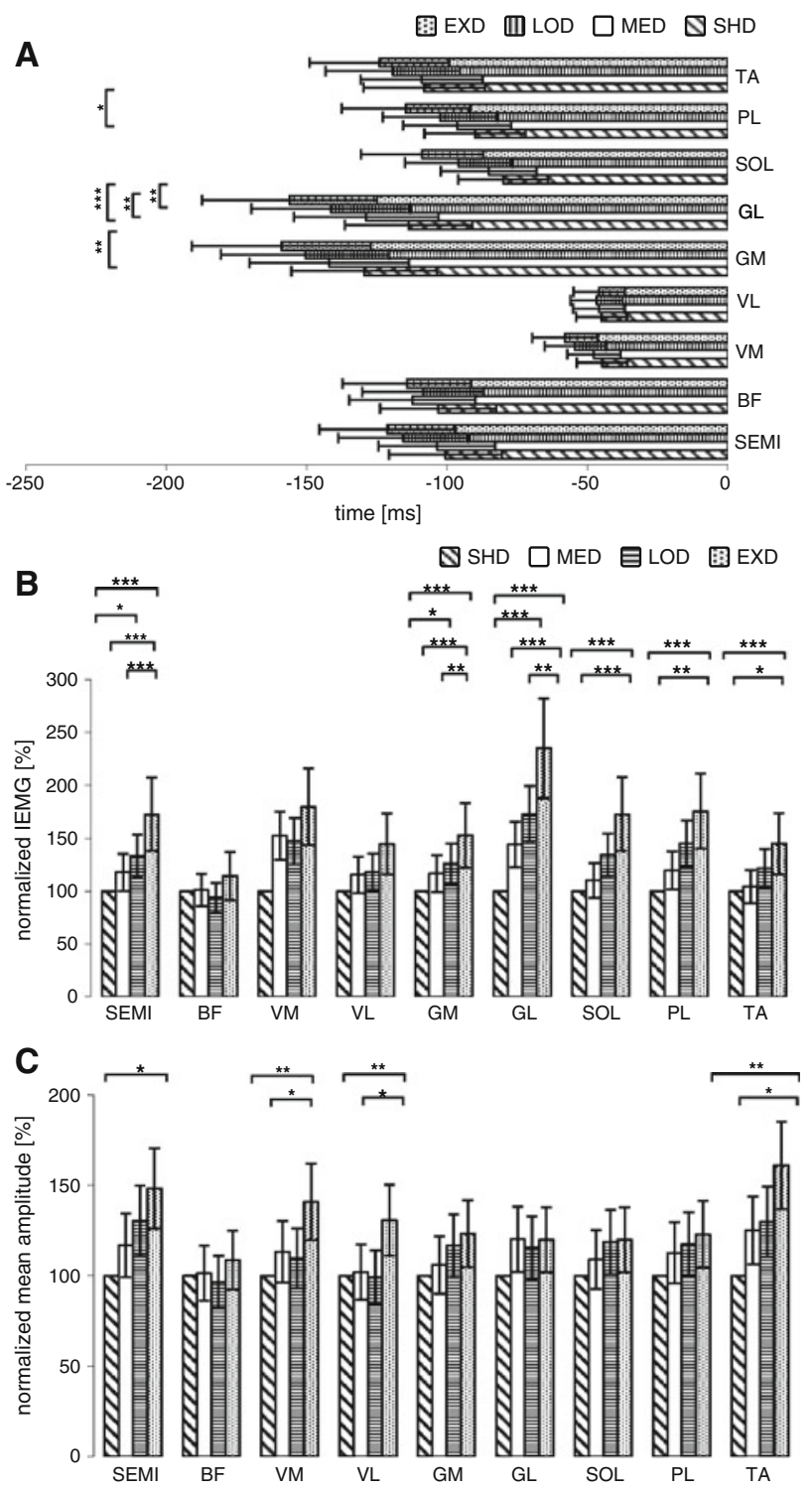

Fig. 4 
$\checkmark$ SHD $\square$ MED 目LOD 国EXD
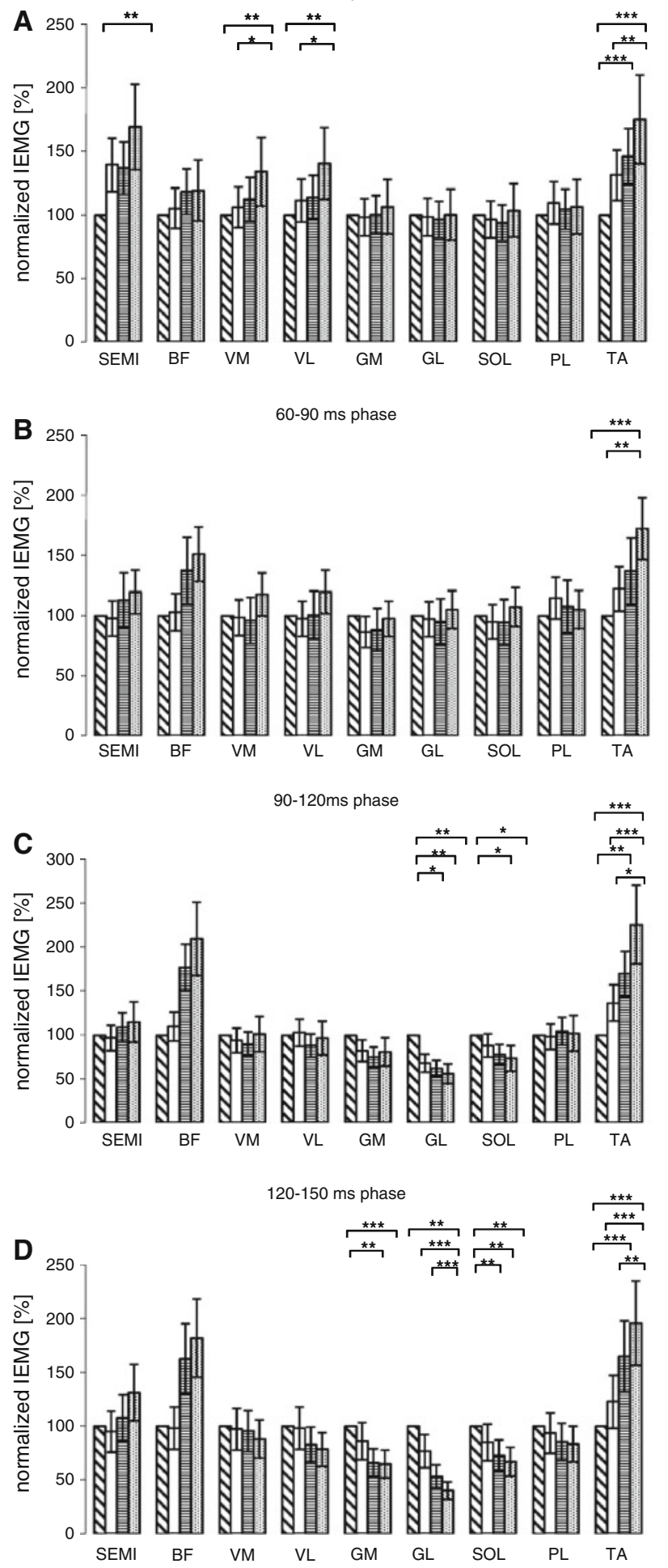

Fig. 5 